\title{
ON THE SYSTEMIC RISK AND OPTIMALITY IN NON-HOMOGENOUS INNOVATION CLUSTERS
}

\author{
Laura GUDELYTË ${ }^{*}$ \\ Department of Financial Engineering, Faculty of Business Management, \\ Vilnius Gediminas Technical University, Sauletekio al. 11, LT-10223 Vilnius, Lithuania \\ *E-mail: gudelyte.l@gmail.com
}

\begin{abstract}
Purpose - to analyse the concept of systemic risk of innovation cluster and show its impact on the optimality of cluster performance as well as to cluster structure.

Research methodology - general overview of research papers and documents presenting concepts and methodologies of evaluation of systemic risk and performance of networked structures as interbank markets and business clusters with regard to asymmetric information, applied research.

Findings - determination of systemic risk in a networked structure that appears together with synergistic effect as a result of collaboration in a networked structure. The clique-based structure appears to be more favourable for innovation cluster performance due to optimal sharing of information and systemic risk. The interpretation of the model of evaluation of systemic risk can be at least twofold: core-periphery, business entities-R\&D institutions, etc.
\end{abstract}

Research limitations - lack of empirical data that cannot be used to implement empirical research on a problem of systemic risk and its modelling.

Practical implications - the conceptual model of evaluation of systemic risk should be useful for understanding and further treatment of measuring risk in a case of innovation management.

Originality/Value - in this paper, the model of evaluation of systemic risk in innovation cluster and its interpretations are provided. The systemic risk is treated as a generalized risk impacting directly or non-directly the performance of an innovation cluster.

Keywords: clique, networking, optimality, systemic risk, structure of innovation cluster, uncertainty.

JEL Classification: O31.

Conference topic: Clusters, Innovations and Circular Economy.

\section{Introduction}

Researchers treating business cluster generating innovations as a networked structure consisting of various entities, however, appoint relatively little significance to their nature. Usually, they dedicate a greater significance to the management structure and the type of hierarchy in the value chain. Some researchers state that a company's linkage has an impact to its rate of innovativeness due to the advantages of networking since networks as communication allow and promote knowledge sharing and flows between interconnected business entities (see, e.g., Ahuja, 2000; D'Alise, Giustiniano, \& Peruffo, 2014). In addition, communication and collaboration between innovation entities ensure the faster innovation process due to their greater social capital (D'Alise et al., 2014). However, networking means not only mutual cooperation in innovation, but also the value creation process and the sequence of the value chain in this case. Despite the fact, that the transfer of technologies and knowledge from research to business is quite complicated (see Lal et al., 2013; Zuniga \& Corea, 2013), the capitalization and transfer of knowledge and technology are defined by various relations between education and science, government and business entities. In any knowledge transfer, an author selling these technologies has more information about the value of asset offered than the potential investors, i.e. partners in innovation cluster. On the other hand, the transferring information (by the supplier) and processing information (by the investor) demands a lot of resources and are, as a result, one of the sources of risk together with information asymmetry. 
On the other hand, networking of innovation cluster means strong dependence on external partners providing knowledge transferring the technology and, as a result, is a relevant channel of contagion through which problems from one business entity belonging to a cluster can spread to other related entities. The channels of contagion within networked structure create and maintain systemic risk, meaning the danger that an initial shock can be amplified and spread when innovation cluster entities react and further transfer it to other entities within the cluster, so that the total effect proliferates largely from the initial default or another unfavourable shock. These contagion phenomena rely on complex network effects since collaborating entities of innovation cluster are interlinked by their diverse claims with business partners within the cluster and with external entities. As a result, various distresses can propagate to neighbouring entities in a way depending on the local features of the network and respective network nodes (Minca \& Amini, 2012).

Cluster networking is focused on establishing cooperation between cluster entities, achieving economies of scale, assisting transfer of knowledge and technologies and mutual learning and in such way promoting individual business development and creation of innovation together. Networking is crucial in innovation clusters and is not necessarily concerning the entities in the same regions and the joint actions have the potential to be highly profitable. Formal management organisation, strategy and rules of activities ensure transparency and accountability and help for collaboration and other activities necessary for creating and commercialization of innovations. As a result, that is the basis for mutual trust, reducing information asymmetry and generating synergies, which are a necessary condition for the success of innovation cluster activity (Gumilar, Zarnić, \& Selih, 2011). Cluster entities can link due to various interests, therefore the relations between them can be based among profit as well as research institutions and other nonprofit organizations.

As a network-based structure that seeks to commercialize innovation, the cluster faces additional uncertainty in comparison to traditional businesses. A key element of the resilience of the innovation cluster is its ability to absorb internal and external shocks without creating disruption to external investors. Unlike as in traditional business, the case of innovation commercialization is much more complicated in terms of uncertainty and risks. Therefore, the necessity to quantify the innovative business risks and elaborate the modelling approaches of the overall impact of various type risks generalized by systemic risk arises. In addition, business risk management (especially in order to avoid technological risks and intense competition) requires optimal co-operation under increased uncertainty between entities of different nature. Also, it is important to create and maintain such structure of innovation clusters that can ensure the efficient resource sharing and resilience to various external and internal shocks with regard to information asymmetry and heterogeneity of business entities and cliques in the cluster.

The scientific literature about innovation clusters as networking-based structures does not provide a wealth of insight into their structure's optimization of performance and systemic risk, and in the context of successful commercialization, basically limited to just a variety of arguments about the nature of collaboration and the geographic becoming increasingly important cognitive distance. There is also no evidence of the impact of the organizational framework of the innovation cluster on its performance (efficiency) and sustainability. Such information is crucial for external partners, especially venture capitalists and other external financiers, who also need to achieve the desired social and economic goals without having to seek attractive returns.

The risk structure of an innovation cluster is complex and somewhat different from the risk of a classic investment portfolio: one part depends on the nature of the innovation and the specific uncertainty associated with it, the other on the structure and level of organization of the innovation cluster. Partially due to the mathematical difficulties in describing the behavior of correlated defaults, this risk analysis is not given enough attention in scientific literature, although it is a practical problem. Therefore, the aim is that the structure of the cluster as a whole that carries out innovative activities should be defined and analyzed in as much detail as possible.

The purpose of the research is to provide a model of evaluation of systemic risk in innovation cluster. In addition, objectives of research is to define the systemic risk in the context of asymmetric information and higher uncertainty due to the creation of innovation and its commercialization, In addition, it is necessary to analyze the resilience mechanisms and examine, what structure of the innovation cluster should be optimal with regard to systemic risk and asymmetric information.

\section{Interaction, network structure optimality, and risk}

Companies belonging to cluster compete for innovation resources and they also promote each other, helping each other adapt to the pressure of competition. This can be a development pattern of synergic competition. Under the pattern of commensalism, cooperation between business entities can be beneficial for both partners. In usual cases, by cooperating with big corporates, small or weak entities can strongly improve their innovation ability, technology, and management level. However, this kind of cooperation does not drive the development of big corporates on a large scale. Finally, under the pattern of proto-cooperation, the business entities in the cluster form a tight and mutually beneficial cooperation alliance (Wang \& Liu, 2016). In most cases, rational companies are reluctant to share their knowledge since they seek to protect their commercial secrets. Also, some researchers emphasize that the output and success of industrial cluster activities depend on the structure of both its local and trans-local linkages (Lorenzen \& 
Mudambi, 2013; Turkina, Van Assche, \& Kali, 2016). However, following Treado and Giarratani (2008), cluster entities can improve companies' ability to transfer their capabilities therein together with access to new markets. Knowledge as one of the most relevant assets generated due networking and output of collaboration is largely codified and mature, often it develops along the process innovation, and it is transferred essentially by the direct personal communication, social and political lobbying, backward and forward linkages (Iammarino \& McCann, 2013). Core and supporting companies, social and hard infrastructure as the most relevant clique is a subset of innovation cluster that interacts within groups of entities through complementary relations and closely linked value chain activities. Proper interaction and transfer of technologies and the management of the potential problems associated with the divergence of views define the evolution of activity in the next stages. Therefore it has a substantial impact on the performance of the cluster in the following stages of activity. It is necessary to take into account the duration of transfer of created new knowledge to business representatives and to properly commercialize them (and protect intellectual property) in order to determine the optimality in this case. All these factors often interplay and change their relevance as clusters develop their activity.

Cluster entities acting independently usually have a limited ability to fit their business models and therefore their performance is impacted by industry factors (Wixted, 2008). Usually, managers of business entities understand that companies can't survive in a vacuum. Therefore they maintain sharing of their knowledge to other entities, so that in turn they may profit from the others' competencies and develop in such a way their social capital and level of competitiveness. As a result, in the cases when cluster entities seek for information about specific technical problems usually representing the weakness of their activities and for which they have no own solution, they naturally try to select those partners, which are the most likely to provide some suitable solutions of their problems (von Hippel, 1987; Schrader, 1991). On the other hand, expertise from a limited field of knowledge only is often insufficient to develop an innovative product in technology-intensive sectors. Therefore innovation cluster is interested to promote fast and direct knowledge sharing through the exchange of competencies. As a result, the cognitive distance between innovation cluster members appears as an important factor impacting the optimality of cluster performance. In order to achieve an effective result, it is first of all necessary to cooperate within the cluster, to know what tasks are being pursued and to achieve gradually those tasks. Cluster members should seek an optimal level of cognitive distance which is closely related to information asymmetry which can also affect the commercialization of innovation, i.e. achieving the main goal of activity of innovation cluster. A number of cases have been analysed proving that mutual trust between business partners, together with the elimination of the substantial part of information asymmetry helps to reduce transaction costs (Boll \& Lill, 2015). Following Nooteboom (2005), one of the crucial tasks of innovation cluster members is to reduce sufficiently the cognitive distance, including moral categories, to implement successfully innovation. The cognitive distance between business entities can be decreased to the level that they have engaged in continued interaction and, as a result, this reduces the novelty value of a partner's cognition, with a diminution of innovation performance (Nooteboom, 2005). In a special case, it can be argued that the technology transfer process is the most complicated aspect of collaboration since it is strongly related to the uncertainty that has an impact on both sides of agreement and which is closely related with risk of inadequate evaluation and competitiveness in the future.

Networks of innovative business entities are not necessarily characterized by geographical proximity (Lazzeretti \& Capone, 2016; Greenhalgh, 2013). Despite the fact that endowment of natural resources or the geographic location close to trading routes showed their relevance in cluster performance, understanding that the diversity of activities and competencies in the same location would increase the individual innovativeness of the companies located within the cluster is challenged by some authors (Hamdouch, 2007). In addition, Baptista and Swann (1998) showed that if business entities are actually more likely to innovate if the labour resources are available, the robust relationship between the activity diversification of cluster and the total innovative propensity of the companies does not exist. Following Simmie (2004) and von Tunzelmann (2003), there is a huge difference in the particular systems of innovation governance between new and old social networks. Typically old social networks are based upon geographically determined social proximity, while relational and cognitive proximity often serves as the basis of new social networks (Lazzeretti \& Capone, 2016). In addition, unlike as old social networks that are based more on historical experience, new social networks may rely on various types of communities everywhere. In such cases, the type of knowledge tends to be both generic and non-systemic, typically with an expensive entry to market and exit, high volatility and small market share and concentration. Also, the nature and types of knowledge often require geographical proximity in such cases (Bathelt, Malmberg, \& Maskell, 2004). In addition, the relative character of new knowledge is generated by the cooperation between commercial entities and other institutions: the openness and therefore the rise of new insights, rules, and standards, etc. are closely related to the importance of external sources of knowledge, and all this happens under the pressure of global competition. In the case of the old social network type, the overall coordination of the innovative activities within innovation cluster is based on the cooperation and competition, and there is not necessarily any hierarchical structure. Due to technological advances, the dissemination of knowledge is ever less impacted by the geographical location but the legal system and the state-implemented innovation policy and support options are strongly dependent on the geographical location. These factors complicate the quantifying of the efficiency and optimality of the innovation cluster's activity. In addition, access to support can distort rational economic behaviour of business entities. These factors are specific, of a qualitative nature and 
necessitate expert evaluation, but their relevance is deciding if it is worth investing in the long run in cluster activities and in the development of innovation cannot in all cases be reasonably determined, therefore, it is advisable the application of quantitative methods.

According to with Everett (2011), the sequence of individual stages of the process generating added value is therefore increasingly shifting into an extensive vertical and horizontal networking among various business entities, other institutions and individuals collaborating in the whole chain of generating added value. This promotes competitors to develop and maintain interconnections in areas of common interest and to create and maintain networking in a niche of the process to generate new added value, i.e., to establish a clique in innovation cluster (Gibbert \& Durand, 2007). However, following Giuliani (2015), empirical analysis shows that the structure of the knowledge sharing in the cluster as a networked structure is closely related with the heterogeneous distribution of knowledge bases and interactions (that can reflect the clique-based structure) and, in addition, knowledge flows are not co-occurring frequently. Typically in such cases, one needs access to entities that can provide complementary knowledge, but one does not know what namely elements of knowledge will be crucial when a dominant design will develop. In addition, it is not known what cluster members and their competitors will survive if the implementation of innovations will be failed. As a result, the network of collaborations for exploration and for exploitation has to be dense.

The willingness of institutions with some future expectations to open up and exchange ideas makes an innovation cluster special case of collaboration. In such way innovation cluster members in some cases tackle similar goals to solve some problems of clients, similar tasks and similar implementation processes, making them more minded to share their social capital together with potential customers. On the other hand, connectivity among cluster members only does not take place for improving competitiveness on the basis of optimization of business processes and generating additional value. In some cases the need to include the final customer in the process of generating more added value appears. Open and trust-based collaboration in the cluster would provide more opportunities for product suppliers to know their customer than a regular supplier-client connection. Direct analysis of needs and the search for technological opportunities through co-operation with suppliers and customers create favourable conditions for new opportunities to emerge and therefore there is also a significant cluster's intrinsic potential to shape the demand for its innovative production itself.

Networking of collaboration is characterized in terms of complementarity and graph nodes: the crucial notion is embedding that can be institutional, structural and relational and that are described in the literature (Nooteboom, 2005). Institutional embedding should regard to external conditions: regulation and norms of conduct, financial support, tax, and legal system, infrastructure, education, R\&D activities, state of the labour market, etc. Structural embedding can be characterized by some quantitative indicators. For example, structural properties of networks are volume, density, variously defined centrality or systemic relevance, and stability of structure with regard to the process of implementing innovations and related systemic risk. Also, it is necessary that the structure of the network ensures flexibility in the case of uncertainty. Relational embedding is treated as the strength and stability of connections. With regard to embedding, an adequate understanding of innovation cluster efficiency demands an understanding of social networks and networking of institutions, and problems of technology transfer from R\&D sector to business entities.

Another implication concerns the duration of partnerships. Highly stable collaboration between innovation cluster entities may be favourable for mutual trust and efficiency of exploitation, but it is not favourable for exploration. It is necessary to maintain variety in order of exploration and, as a result, the generation of new ideas and the opportunities to co-operate. Some researchers state that the more lasting the established relationship is the more stable the networking should be, what is beneficial for the establishment of mutual trust relations between cluster entities and a shared code of conduct and strengthen the exchange of knowledge and other information between entities (Ahuja, 2000; Salman \& Saives, 2005). On the other hand, following a lot of other studies, the relationship of business entities in innovation cluster should not be too long due to the risk of being locked by this relationship and ossification that leads to the lack of new knowledge and ideas and, as a result, to recession of the cluster (Tolstoy \& Agndal, 2010). Also, it means that lasting network relationship is not so suitable for the requirement of flexible specialization. They propose a path hypothesis on how link property influences the impact of cluster members' restructuring resilience on cluster resource collaboration and integration. The claim of a negative effect of the duration of a relationship is characterized by the condition that the companies involved have no contacts outside the relation, pertaining to the subject of collaboration. On the other hand, when both collaborating cluster entities have relations outside cluster with non-overlapping networks, they have an opportunity to refresh their competences with novel insights that keep their relation within the cluster with more potential vibrant (Nooteboom, 2005).

\section{Impact of cliques to networking and optimality of innovation cluster}

Flat and efficient structures are crucial for successful performance in international markets where quick feedback and organisational innovations are substantial (Gumilar et al., 2011). The strict definition of a clique in the context of networking analysis is more narrow and precise than the general notion of a high local density. A clique is a subset of a network in which the entities are more closely and intensely connected to one another than they are to a remaining 
set of the cluster members that can be characterized by the maximum number of entities having all possible connections among themselves, i.e. complete sub-graph in terms of graph theory. The smallest cliques are composed of two partners. On the other hand, dyads can be "extended" to become more and more inclusive - forming a strong or closely connected set of entities in the cluster network. Therefore one can expect that cognitive distance is more appropriate in cliques and as a result in the whole innovation cluster as it helps to reduce operational risk and costs. New knowledge of narrow specialization and technology transfer is usually more effectively implemented in small and flexible structures - cliques that help a larger structure, i.e. cluster, to maintain competitiveness and facilitate the transactions between each partner within cluster, since not in all cases direct communication between huge number of separate entities is efficient (especially when large and small bodies collaborate within cluster). Therefore, it is likely that, when the cluster structure is clique-based, allowing more focused information within the cluster to be shared, it is easier to achieve the optimal cognitive distance and cope with innovative activity. In decentralised networks, in most cases, the scope of cooperation extends only to a narrow, "noncore" segment of company functions, and the partners are more or less equal in their cooperation.

Lerch, Provan, and Sydow (2008) showed that companies simultaneously exploring and exploiting regional networks of different relational dimensions are more efficient in transferring knowledge in innovation activities and are likely to be more innovative than other firms within the cluster that keep an only single connection to different partners. In segmented clusters, cliques are formed within the network, within which the linkages among the cliques are weak, occasional or completely non-existent (Futó, 2014). Following Futó (2014), segmentation in the business cluster may develop, if certain cliques evolve particular culture or if some more relevant members of the cluster develop linkages with only a subset of members. In such cases, co-operation is satisfactory within several cliques, but weak or non-existent between these groups of companies. As a rule, segmentation within a cluster may evolve:

- if the cluster involves well identifiable subgroups of companies with characteristically different industrial cultures;

- if the cluster is organised around some strong companies which are more interested to cooperate with their traditional subcontractors, which are entities of the cluster as well, than with other cluster members.

Also, segmented clusters are less sustainable than clusters without cliques since it means the limited ability of the organisation to reorganize and adapt to the changed environment the cluster structure. Paytas, Gradeck, and Andrews (2004) showed the impact of these organizations as the development of innovating companies depends crucially on the alignment and coordination between the R\&D institutions and the industrial specializations of the companies. Cliquebased structure of cluster is favourable for that and allows timely and quick clique-level decisions, and decisions taken across the cluster can be considered more than once. Typically this is beneficial, as more detailed considerations often help to reduce the majority of the operational risk, in other cases, it can lead to additional time costs and loss of efficiency. Availability of efficient coordination and the cooperation between various cluster entities and the reach of balanced compromises between centralized and decentralized levels for decision-making processes also are equally important. Therefore the presence and sustainability of an innovation cluster optimal activity require both an institutional and organizational cohesion and the so-called cognitive distance between the networked business entities in the cluster (Nooteboom, 2005; Depret \& Hamdouch, 2006, 2007).

At first glance, cliques may partially limit direct collaboration between cluster members from different cliques. A cluster consisting of cliques can be treated as a reduced economic model in which each clique defends its interests and seeks to maximize its long-term profit, which would be generated by the innovation creation and commercialization processes. Decentralized structure with cliques allows the cluster to respond more quickly to external changes as well as effectively disseminate the most relevant and concentrated information across the entire cluster because in this case, clique members have more opportunities to know in more detail their actual partners in a clique than in other cluster network positions. In addition, the clique-based structure is favourable for making management decisions in the absence of information asymmetry (otherwise, the absence of information asymmetry may come from negotiations and coordination of interests, which can lead to a deadlock. The clique means that the interests within it are already aligned and remain to combine them at a higher level - at the cluster management level). As a result, the structure of cluster becomes similar to homogeneous and therefore it is favourable for the fast and equivalent exchange of information (new knowledge about new technologies), to directly and expeditiously conduct transactions between cluster members. In addition, cliques help reduce the time costs of finding targeted partners (without generating information noise and making cooperation more efficient in the enterprise cluster.

\section{On the conditions for optimal performance of innovation cluster}

Trust. Following Nooteboom (2005), the dense networking structure is also needed for a reputation mechanism. Mutual trust is necessary for cooperation that can help deliver large volumes of products to the market faster, facilitate collaboration with other companies and R\&D institutions and accelerate the creation of innovative products. Companies enter into clusters sometimes hoping for a quick result, i.e., that only joining a cluster will help them to increase their competitiveness, save money or bring other benefits. However, without triggering the initiative, in the absence of cooperation in the cluster, the result is not as expected at the time of accession. 
The social networking means that trust between decision making entities may be of crucial importance within the cluster. These trust relations are expressed by a variety of features, such as informal alliances, joint ventures, joint lobbying, etc. In addition, trust-based relations between key decision-makers in different members of the cluster are assumed to reduce transactions costs (Iammarino \& McCann, 2006). Although the localization of activities within a geographically-bounded space is neither a sufficient ground nor a systematic condition for the existence of an innovative cluster, one should recognize the fact that the firms and other entities involved in interacting in innovation processes or common projects are necessarily located somewhere (Hamdouch, 2007). Following Gordon and McCann (2000), the social network model is explained on the basis of the assumption of non-opportunistic behaviour, the possibility of the network as an increasingly predominant form of economic governance needs to be accounted for, particularly as it pushes the concept of proximity beyond just a spatial dimension. Geographical and cognitive proximity help to maintain trust, which is not so simple to create and maintain over virtual events or occasional meetings. However, collaboration in implementing project activities and regular meetings help to create informal relationships, and often relevant knowledge is shared in random conversations. Also, the lack of relevant and timely provided information, the prevailing mistrust between business entities, propensity to discover a competitor in a potential partnership, and not the opportunity of partnership holds back the cluster's development. In addition, the lack of choice of suitable communication media prevents the dissemination of information and knowledge. Dissemination of the latest information among business entities is based on expectations of future benefits, as well as the need for confidence and understanding that quality cooperation is essential for the effective development of innovation. Networks for exploration entail a wide scope of open relations based on trustworthiness.

Optimal allocation of resources. Activities in the innovation cluster mean flexible manufacturing and design of business ideas under the assumption that clustering allows intense resource sharing in order to realize complementarities and achieve positive synergy. Usually improvement of quality and sharpened ability to utilize many advantageous conditions of the cluster with a change of market and appearance of newly added value chain become a competitive power and optimal allocation of the resource. Improving resource utilization efficiency is possible fully realizing complementarities within the cluster. Development and coordination among cluster members, strengthening of complementarities of each company and convenient communication can help for optimal resource sharing, zero inventory and quality management in an all-around way, making more full use of the social resource. The other is outsourcing. After comparing internal production and organization expense with market trading cost, guidance of cluster development and division and coordination benefit urge enterprise to outsource part of its own activity to other enterprise and enlarge production scale or lower cost by the use of social resource through outsourcing and fully exploit the potential of partners within business cluster in such way. In addition, a strong specialization of cluster entities also means that the companies assume a significant risk, because if technology or specialization suddenly becomes unnecessary, then it would either the collapse of that company or the active entities of innovation cluster. It is a case when innovative activity looks less attractive and together with higher uncertainty generates additional risk.

Impact of main external conditions. Besides internal cluster synergy factors, the optimality of the innovation cluster performance is impacted by external conditions and factors determining the whole operating environment. The business cluster as an organization cannot effectively operate under the conditions of a rigid and corrupt bureaucratic administrative regulation or judicial system that is unable to resolve disputes quickly and correctly. Some aspects of the business environment, such as legal or tax systems, affect all sectors. The legal framework and tax planning possibilities have a significant impact on the organization of the cluster, which contributes to distorting the economic behaviour of cluster members and affects the optimality of the cluster business, but their dominance itself does not create preconditions for the long-term economic cluster members' viability. Usually external economies of collective bargaining and generating synergies in clusters, but deriving from work with current and potential customers are another important aspect of cluster economies (Yeung et al., 2004). In developed economies, these systems operate more efficiently, therefore, the internal microeconomic environment has a greater impact on the cluster performance: sufficient level of demand, easy availability of potential and existing markets, favourable tax system, sufficient labour force supply in the labour market (including the potential of local higher education institutions) opportunities for fast development of business (for construction, acquisition of land and premises), convenient financing system for innovation development projects and other reasons.

Presence of a market opportunity is the crucial factor for the existence of innovative business: following Ketels and Protsiv (2013), many clusters are active in fields that are not directly related to typical goal to generate profit, etc. Market opportunity usually attracts companies, and their needs to draw cluster initiatives into these fields (Ketels, 2015). Also, technological opportunities and new technological solutions often are generated due to academic research in R\&D sector that is often outside the innovative cluster and business companies and the respective industry sector.

Other relevant factors. In some cases innovation cluster can be established like any start-up because the market is small (and therefore the risk to failing of implementation of innovations is much smaller in comparison with traditional "big" markets), the conditions to begin business (i.e., legal framework, taxes applied, etc.) are quite favourable. Specific elements of the business environment, e.g., the presence of strong R\&D institutions are an additional factor for the development of innovative activities in the cluster (Manning, Massini, \& Lewin, 2008). As a result, often companies, start-ups or other forms of innovation business succeed in the market and during time become 
the anchor of following spin-offs and other firms that can enter into a cluster. Often clusters are also established on the basis of older clusters that have lost potential market but found a new way to save, transform, maintain and develop their competitiveness and innovative business ideas.

Clusters develop when transactions across members are feasible and there are specific factors in a location or potential of intelligence of cluster members that provide a nucleus for its development. The concentration of cluster members in one area helps to reduce costs in production, logistics, etc.). However, it does not make a more remarkable impact on the dissemination of relevant knowledge. However, it is likely that cluster members can have a wider range of approaches for developing business visions and innovations under higher local proximity, and such things could greatly enrich the organization.

\section{Model of evaluation of systemic risk in non-homogenous cluster}

We consider a network model with regard to various types of relations and in which one can model cascades of defaults or illiquidity cases and following feedback effects to the external conditions like a sudden price jumps of necessary assets (Degryse \& Nguyen, 2004). The contagion in innovation cluster can occur due to illiquidity. On the other hand, one can occur due to external investors (typically venture capital institutions) expectations: when one group of investors face the withdrawal of another group of investors, they also can try to withdraw their investments which are motivated by the uncertainty about the future development of innovative activities and fear, that later they withdraw, the less probability is that entities of the innovation cluster can satisfy their expectations and claims. The contagion in innovation cluster is described by the $N \times(N+M)$ - order matrix $X$ of bilateral exposures in order to analyse the propagation features of defaults of innovation cluster entities. The matrix of bilateral exposures summarizes the bilateral exposures of cluster entities toward the other $(N-1)$.

$$
X=\left[\begin{array}{ccccc|ccc}
x_{11} & \ldots & x_{1 j} & \ldots & x_{1 N} & w_{1 N+1} & \ldots & w_{1 M} \\
\vdots & \ddots & \vdots & . & \vdots & \vdots & & \vdots \\
x_{i 1} & \ldots & x_{i j} & \ldots & x_{i N} & \vdots & & \vdots \\
\vdots & . & \vdots & \ddots & \vdots & \vdots & & \vdots \\
x_{N i} & \ldots & x_{N j} & \ldots & x_{N N} & w_{N N+1} & \ldots & w_{N M}
\end{array}\right],
$$

where $x_{i j}$ means the gross exposure of the $i$ th cluster entity to the $j$ th cluster member, $w_{i j}$ means the gross exposure of the $i$ th cluster core entity to the $j$ th periphery member (or external business partner) $a_{i}$ represents the assets of $i$ th entity inside innovation cluster, $l_{j}$ represents the domestic liabilities inside innovation cluster of $j$ th entity, and $e_{i}$ represents the external claims of $i$ th cluster member:

$$
\sum_{j=1}^{N} x_{i j}=a_{i}, \sum_{i=1}^{N} x_{i j}=l_{j} \text { and } \sum_{j=N+1}^{M} w_{i j}=e_{i} .
$$

The matrix of bilateral exposures $X$ is unknown due to confidentiality of business deals and therefore must be estimated. The systemic risk of innovation cluster means the impact of the failure (or default) of each of the $N$ entities belonging to the core of cluster and each of the $M$ periphery entities for a fixed loss given default. The initial failure is supposed to be a cause of the following failure when the exposure of one innovation cluster member to failed entities is large enough to offset its capital. In addition, the $i$ th entity of innovation cluster collapses due to previous failures when

$$
C_{i}-\theta \sum_{j=1}^{N} \lambda_{j} x_{i j}-\theta \sum_{j=N+1}^{M} \lambda_{j} w_{i j}<0,
$$

where $C_{i}$ means the capital of $i$ th cluster entity, $\theta$ means the loss given default rate and $\lambda_{j}$ is a dummy variable that is equal to 1 if $j$ th cluster member defaults and 0 otherwise. We suppose loss given default rate to be identical for all failed entities of the innovation cluster. The initial default of any cluster entity may cause several rounds of following failures. Assuming that usually in the bankruptcy situations of business entities the netting procedures are quite rare, the gross exposures of respective entities $x_{i j}$ and $w_{i j}$ are used rather than net exposures $x_{i j}-x_{j i}$. The contagion, i.e., the propagation of systemic risk stops when cluster entities that failed during the last round do not cause any following defaults, i.e., when the structure of remaining part of innovation cluster represented by collaboration network, becomes again stable.

The approach of aggregate exposures is based on the observed aggregate parameters $a_{i}$ and $l_{j}$, which provide only incomplete information on bilateral liabilities and exposures between cluster entities, i.e. the sum of the elements of respective column and a row of the matrix $X$. This information is partial only, therefore it is necessary to assume that 
cluster entities seek to maximise the dispersion of their activities. With the appropriate standardisation, it would be equivalent to assuming a matrix $X^{0}$ such that $x_{i j}=a_{i} l_{j}$. This is equivalent to minimising the distance function (measured by the relative entropy) between $X^{0}$ and the constrained matrix:

$$
\min \sum_{i=1}^{N} \sum_{j=1}^{N} x_{i j} \log _{e}\left(\frac{x_{i j}}{x_{i j}^{0}}\right)
$$

subject to constraints

$$
\sum_{j=1}^{N} x_{i j}=a_{i} \text { and } \sum_{j=1}^{N} x_{i j}=l_{j} \text { and } x_{i j} \geq 0 ; x_{i j}=0 \text { when } x_{i j}^{0}=0 \text { and the assumption that }\left(0 \log _{e}(0 / 0)\right)=0 .
$$

This model let us treat an innovation cluster as a risky set of entities, impacted by external shocks, which, as a social network that shares the trust and resources of each individual member, influences the viability to the entire cluster thus a risk becoming not only idiosyncratic but systemic. In this case, however, it is difficult to establish the degree of interconnection between cluster members or the likelihood of related insolvencies on the basis of empirical data, as data are largely unavailable mainly due to the relatively rare occurrence of related insolvency events. Unlike as in the case of the square matrix, in this model, the cluster structure is assumed to be non-homogeneous and consisting of two parts: the core that generates a major impact on the members of the innovation cluster and the periphery entities which are less significant to the common activity. The structure of the innovation cluster described by presented formulas also corresponds to the risk-sharing in the innovation cluster. In addition, this model can be used to describe systematic risk when cluster shares its risk with external partners. It would not be useful for the success of the commercialization of the cluster, but in the event of failure, the risk-sharing would provide more opportunities to continue the creation of innovations and their commercialization activities.

Remark. It is possible to treat this model in another way: to divide the cluster structure with regard to transfer of specific academic knowledge and new technologies: the core of the cluster should represent the R\&D sector providing necessary information for business entities belonging to the periphery of innovation cluster in terms of knowledge sharing.

\section{Location in network, systemic risk and optimality of networking in cluster}

In fact, each element of the structure is relevant for competition of the cluster. First of all, core companies hold knowhow and are leaders in developing business ideas. Other cluster members can be less known. Competitiveness of relevant members of cluster strongly depends on the activity of other partners in the cluster, i.e., typically suppliers who deliver raw materials, products, provide additional services, etc. and know-how holders that provide relevant technological solutions and define the potential of future demand. As a result, the quality of the supplier has a strong impact on the well-being of the whole cluster (Babkin, Kudryavtseva, \& Utkina, 2013). Typically the core set containing highly specialised and complementary companies having the biggest potential to innovate is at the network centre, i.e. having the highest systemic relevance. These entities form the critical core of the cluster, i.e. the most relevant clique, and demonstrate distinctive characteristics that are dominant and often unique in the extent of the innovation cluster. As a result, the more centrally the core entities locating in the cluster network have, the more conducive their transformation and growth will be to integration and coordination of cluster resources. Looking the profile of innovation cluster structure, a central position yields power and relevant influence, but, on the other hand, there are lots of constraints on economic behaviour due to many possibly divergent interests and complementarities (Krackhardt, 1999).

Systemic risk structure and the problems induced by higher volatility due to the diverse and numerous sources of risk. Besides the well-known risk structure determined by the regulators financial sector, there exist additional sources of risk in the innovation industry, namely, higher than usual uncertainty and volatility in an innovative case. This is namely what determines the involvement of venture capitalists and the attitude towards the business they create as a high-risk and fast-growing investment opportunity. All of these risks can, to an appropriate extent, lead to systemic risk in the innovation cluster. This is due to the technology transfer process, inevitably accompanied by information asymmetry, numerous additional risks associated with the demand for the commercialized product, technologies, etc., technological risks (potential competitors create more advanced technology or applied new technologies can be pirated, etc.

Performance of enterprises, the capture of resources and other actions can be treated as the function where the enterprises lie in the innovation network. Following Qian, Yang, and Xu (2010), different network positions represent different opportunities of business entities to acquire new knowledge and resources and different level of systemic relevance in the extent of the innovation cluster. In addition, Owen-Smith and Powell (2004) also stated that enterprises occupying dominant positions in a network can consolidate different entities through their positions to acquire and control resources to ensure complementarities in innovative activities. A well-known feature of structure centrality 
characterizes the level of opportunities within cluster and coordination of activities. Core and supporting companies, social and hard infrastructure interact within a related cluster through complementarity. Typically the core set of complementary entities having the biggest potential to innovate is at the network centre, i.e. having the highest systemic relevance (highest centrality) and they serve as the critical core of the cluster (in the special case - the most relevant clique), and display distinctive characteristics that are unique in the extent of activities of innovation cluster. In addition, the more centrally the core entities locate in the cluster network, the more conducive the transformation and growth of the core enterprises is to integration and coordination of cluster resources and collaboration and, as a result, it might lead to structural changes of development of innovative activities and generate systemic risk. A central position reflects the dominance, but possibly also constraints on behaviour due to the possibly divergent interests (Krackhardt, 1999) and the necessity to coordinate activities.

The phenomenon of systemic risk in the innovation cluster is similar to that of the banking sector systemic. Examples of systemic risks of the banking sector (Cont, Moussa, \& Santos, 2010) show that a star-forming can be riskier network structure, i.e., when a large-scale innovation-driven business is in the process of developing a clusterbased structure that can protect itself from the domino effect inside the cluster. When the entire clique fails, but other entities (another cliques) of the cluster are saved the cluster part depends on one or more significant agents (such as those with the highest commitment to other business cluster entities) whose failure or failure can have a significant negative effect on other cluster entities and in some cases cause a chain reaction of failures in the context of banking systemic risk known as domino. In principle, the systemic risk phenomenon in the cluster is similar to that of the banking system's systemic risk in the public finance system. On the other hand, in this case, another component is also significant: if innovation activity is too risky and as a result, the main cluster entities suffer significant losses, and this effect may overcome other cluster members depending on the activities of the main cluster members, possible domino effect. Resilience to internal and external negative effects of the star cluster structure is not optimal, and optimal would be as homogeneous as possible, i.e. when all cluster members are generally considered to be approximately equivalent. However, in such cases, cluster management would suffer: when an organization is composed of roughly equivalent entities in negotiation, it is likely that it would be more difficult to make decisions and reach compromises and agreements, making it difficult to negotiate and coordinate the process. Due to these reasons, the problem of the optimality of the activity (and structure) of the innovation cluster that creates the innovation can be treated as a problem of optimal portfolio management. In special cases, the clique-based and partly "homogenized" innovation cluster structure can protect against the so-called domino effect inside the cluster (when the entire clique fails, but other members (forming other cliques) are saved. However, decomposition of activities and systemic risk management sometimes can be controversial issues in order to ensure the viability of the cluster's activities and the development of innovation.

\section{Conclusions}

Research literature has no unambiguous insights on which cluster structure provides the best conditions for achieving goals. Systemic risk as an important feature of networked structure and a generalization of all types of innovative business risks is not sufficiently analysed in research literature concerning business clusters. However, in the case of innovation clusters, an important condition of optimal activity is the duration needed for innovation to emerge that is not easy to apply in typical cluster networking and its configuration since innovation creation is a unique process.

The propensity and the need for long-term cooperation, openness to ideas, goodwill and a strong idea of innovation can be essential conditions for a successful cluster's activity. Also, it is widely acknowledged that sufficient mutual trust among cluster entities provides preconditions for an effective resource allocation and utilization and reduction transaction costs, but does not in itself provide innovation for commercial success and thus the optimal performance of innovation cluster.

In this paper, I proposed to apply the concept of systemic risk as a generalized risk concept in order to evaluate quantitatively the resilience of an innovation cluster to internal and external shocks. It can be modelled using the algorithms applied to collaboration networking in banking sectors (interbank markets). The proposed model of evaluation of systemic risk can be treated in various ways with regard to the formulation of exercise and the structure of innovation cluster: it is possible to model the weights of interlinkages between core and periphery of innovation. On the other hand, using the same model, it is possible to evaluate systemic risk between commercial entities and R\&D institutions implementing new technologies. Finally, it is possible using the same formulas to model the systemic risk of the innovation cluster as an impact of external collaborating entities.

Clique-based structure of innovation cluster means more concentration of information and more homogeneity in networking. Decentralized structure with cliques allows the cluster to respond more quickly to external changes as well as effectively disseminate the most relevant and concentrated information across the entire cluster. 


\section{References}

Ahuja, G. (2000). Collaboration networks, structural holes, and innovation: a longitudinal study. Administrative Science Quarterly, 45(3), 425-455. https://doi.org/10.2307/2667105

Babkin, A., Kudryavtseva, T., \& Utkina, S. (2013). Identification and Analysis of Industrial Cluster Structure. World Applied Sciences Journal, 28(10), 1408-1413.

Bathelt, H., Malmberg, A., \& Maskell, P. (2004). Clusters and knowledge: local buzz, global pipelines and the process of knowledge creation. Progress in Human Geography, 28(1), 31-56. https://doi.org/10.1191/0309132504ph469oa

Bol, J. C., \& Lill, J. B. (2015). Performance target revisions in incentive contracts: do information and trust reduce ratcheting and the ratchet effect? The Accounting Review: September, 90(5), 1755-1778.

Cont, R., Moussa, A., \& Santos, E. B. (2010). Network structure and systemic risk in banking systems. SSRN Electronic Journal. https://doi.org/10.2139/ssrn.1733528

D'Alise, C., Giustiniano, L., \& Peruffo, E. (2014). Innovating through clusters. Regular paper. International Journal of Engineering Business Management. Special Issue: Innovations in Pharmaceutical Industry, 6(28), 1-14. https://doi.org/10.5772/59028

Degryse, H., \& Nguyen, G. (2004). Interbank exposures: an empirical examination of systemic risk in the Belgian banking system (Working Paper No. 43). National Bank of Belgium.

Depret, M.-H., \& Hamdouch, A. (2006). Echelles spatiales, formes de proximité et logiques institutionnelles: Esquisse d'une approche co-évolutionnaire des dynamiques de changement technologique dans la pharmacie et les biotechnologies. In Cinquièmes Journées de la Proximité: La proximité, entre interactions et institutions, Bordeaux, 28-30 June, 31. https://doi.org/10.3917/inno.025.0085

Depret, M.-H., \& Hamdouch, A. (2007). Changements technologiques, logiques institutionnelles et dynamiques industrielles: Esquisse d'une approche co-évolutionnaire appliquée à l'industrie pharmaceutique et aux biotechnologies. Innovations, 25, 85-109. https://doi.org/10.3917/inno.025.0085

Everett, K. (2011). Designing the networked organization (the strategic management collection). New York: Business Expert Press. https://doi.org/10.4128/9781606491966

Futó, P. (2014). The network structure of Hungarian business clusters. Vezetéstudomány/Budapest Management Review, 45(1), 41-54.

Gibbert, M., \& Durand, T. (2007). Strategic networks. Learning to compete. Blackwell Publishing, Inc.

Giuliani, E. (2005). The structure of cluster knowledge networks: uneven and selective, not pervasive and collective (DRUID Working Paper No. 05-11, pp. 1-22). Copenhagen Business School, Department of Industrial Economics and Strategy/Aalborg University, Department of Business Studies.

Gordon, I. R., \& McCann, P. (2000). Industrial clusters: complexes, agglomeration and/or social networks? Urban Studies, 37(3), 513-532. https://doi.org/10.1080/0042098002096

Greenhalgh, B. (2013). The role of international cluster cooperations in Europe 2020; Clusters in Europe III. Manchester Metropolitan University Business School, Enterprise Fellow.

Gumilar, V., Zarnić, R., \& Selih, J. (2011). Increasing competitiveness of the construction sector by adopting innovative clustering. Inžinerine Ekonomika - Engineering Economics, 22(1), 41-49. https://doi.org/10.5755/j01.ee.22.1.217

Guo, Y. (2012). Research on innovation risk management based on bayesian risk decision-making. International Journal of Business Administration, 3(1), 21-30. https://doi.org/10.5430/ijba.v3n1p21

Hamdouch, A. (2007). Innovation clusters and networks: a critical review of the recent literature. In 19th EAEPE Conference, Universidade do Porto, 1-3 November (pp. 1-30). Retrieved from https://www.fep.up.pt/conferencias/eaepe2007/ papers\%20and\%20abstracts_cd/hamdouch.pdf

Iammarino, S., \& McCann, P. (2006). The structure and evolution of industrial clusters: Transactions, technology and knowledge spillovers. Research Policy, 35(7), 1018-1036. https://doi.org/10.1016/j.respol.2006.05.004

Iammarino, S., \& McCann, P. (2013). Multinationals and economic geography: location, technology and innovation. Edward Elgar Publishing. https://doi.org/10.4337/9781781954799

Ketels, C. (2009). Clusters, cluster policy, and Swedish competitiveness in the global economy (Expert report No. 30). Sweden's Globalisation Council.

Ketels, C., \& Protsiv, S. (2013). Clusters and the new growth path for Europe (Working Paper No. 14, pp. 1-65). Welfare, Wealth, Work.

Krackhardt, D. (1999). The ties that torture: Simmelian tie analysis in organizations. Research in the Sociology of Organizations, 16, 183-210.

Lal, B., Holloman, S. S., Mahoney, R., Martin, C. A., Koopman, K. A., Hallion, R. P., \& Rood, S. A. (2013). Expediting the transfer of technology from government laboratories into the aeronautics industry (IDA Paper P-4952). Retrieved from https://www.ida.org/idamedia/Corporate/Files/Publications/STPIPubs/ida-p-4952.pdf

Lazzeretti, L., \& Capone, F. (2016). How proximity matters in innovation networks dynamics along the cluster evolution. A study of the high technology applied to cultural goods. Journal of Business Research, 69(12), 5855-5865. https://doi.org/10.1016/j.jbusres.2016.04.068

Lerch, F., Provan, K., \& Sydow, J. (2008). Network integration in regional clusters and firm innovation - a comparison of measures. Paper presented at the Academy of Management Annual Meeting August 8-13, Anaheim, California. 
Lorenzen, M., \& Mudambi, R. (2013). Clusters, connectivity and catch-up: Bollywood and Bangalore in the global economy. Journal of Economic Geography, 13(3), 501-534. https://doi.org/10.1093/jeg/lbs017

Manning, S., Massini S., \& Lewin, A. Y. (2008). A dynamic perspective on next-generation offshoring: the global sourcing of science and engineering talent. Academy of Management Perspectives, 22(3), 35-54. https://doi.org/10.5465/amp.2008.34587994

Minca, A., \& Amini, H. (2012). Mathematical modeling of systemic risk. In E. Kranakis (Ed.), Advances in network analysis and its applications (pp. 1-20). Berlin, Heidelberg: Springer-Verlag.

Nooteboom, B. (2005). Innovation, learning and cluster dynamics (Discussion Paper No. 2005-44). Tilburg University, Center for Economic Research.

Owen-Smith, J., \& Powell, W. W. (2004). Knowledge networks as channels and conduits: The effects of spillovers in the Boston biotechnology community. Organization Science, 15(1), 5-21. https://doi.org/10.1287/orsc.1030.0054

Paytas, J., Gradeck, R., \& Andrews, L. (2004). Universities and the development of industry clusters. Carnegie Mellon University, Center for Economic Development.

Qian, X., Yang, Y., \& Xu, W. (2010). Enterprise network location, absorptive capacity and innovation performance - an interactive effect model. Management World, 5, 118-129.

Salman, N., \& Saives, A.-L. (2005). Indirect networks: an intangible resource for biotechnology innovation. R\&D Management, 35(2), 203-215. https://doi.org/10.1111/j.1467-9310.2005.00383.x

Schrader, S. (1991). Informal technology transfer between firms: cooperation through informal trading. Research Policy, 20, 153170. https://doi.org/10.1016/0048-7333(91)90077-4

Sydow, J., \& Provan, K. G. (2014). Cliques within clusters - multidimensional network integration and innovation activities. Retrieved from https://www.researchgate.net/publication/237565372_Cliques_within_Clusters___Multidimensional_ Network_Integration_and_Innovation_Activities

Tolstoy, D., \& Agndal, H. (2010). Network resource combinations in the international venturing of small biotech firms. Technovation, 30(1), 24-36. https://doi.org/10.1016/j.technovation.2009.06.004

Treado, C. D., \& Giarratani, F. (2008). Intermediate steel-industry suppliers in the Pittsburgh region: a cluster-based analysis of regional economic resilience. Economic Development Quarterly, 22(1), 63-75. https://doi.org/10.1177/0891242407311268

Turkina, E., Van Assche, A., \& Kali, R. (2016). Structure and evolution of global cluster networks: evidence from the aerospace industry. Journal of Economic Geography, 16(6), 1211-1234. https://doi.org/10.1093/jeg/lbw020

von Hippel, E. (1987). Cooperation between rivals: informal know-how trading. Research Policy, 16, $291-302$. https://doi.org/10.1016/0048-7333(87)90015-1

Wang, X., \& Liu, J. (2016). A Novel Modelling Study on Innovation Co-Evolution Mechanisms of Automobile Industrial Clusters. International Journal of Simulation Systems, Science \& Technology, 32(17), 32.1-32. http://ijssst.info/

Wixted, B. (2008). Cluster rents: strategic organisations or/and system resources? Paper to be presented at the 25th Celebration Conference 2008 Entrepreneurship and Innovation - Organizations, Institutions, Systems and Regions, Copenhagen, CBS, Denmark, 17-20 June.

Zuniga, P., \& Corea, P. (2013). Technology transfer from public research organizations: concepts, markets, and institutional failures. The Innovation Policy Platform. Retrieved from https://www.innovationpolicyplatform.org/sites/default/ files/rdf_imported_documents/TechnologyTransferFromPublicResearchOrganizations.pdf 